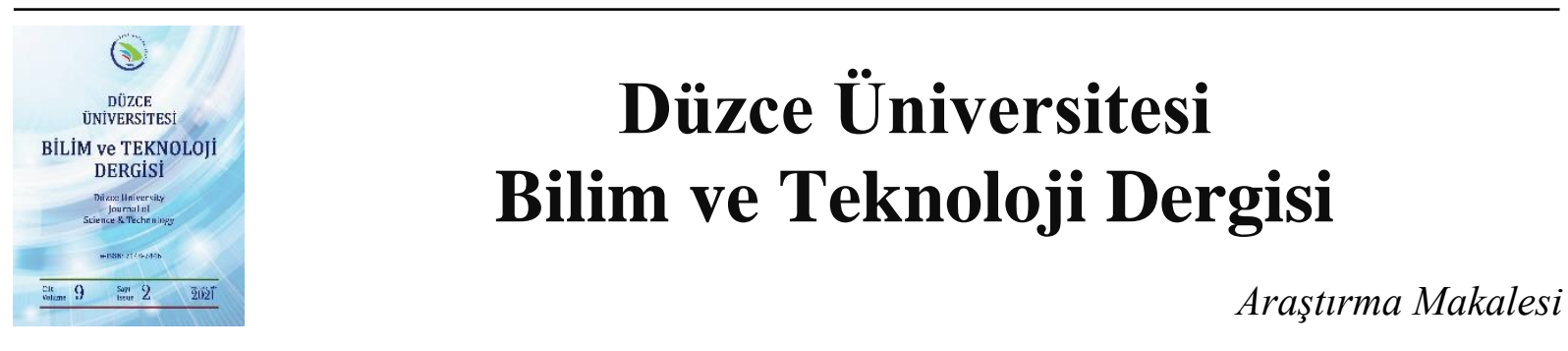

\section{Taguchi Metodu ve Gri İlişkisel Analizi Kullanılarak 1,2316 Paslanmaz Çeliğin (R65) Mikro-Elektro Erozyon Delme Kabiliyetinin Değerlendirilmesi}

\author{
Sitkı AKINCIOĞLU ${ }^{\text {a,* }}$ \\ ${ }^{a}$ Makine Resim ve Konstrüksiyon Bölümü, Gümüşova Meslek Yüksekokulu, Düzce Üniversitesi, Düzce, \\ TÜRKIYE \\ * Sorumlu yazarın e-posta adresi: sitkiakincioglu@duzce.edu.tr \\ DOI:10.29130dubited.833720
}

\section{ÖZET}

Bu çalışmada, R65 paslanmaz çeliğin Mikro-Elektro Erozyon İşleme (Mikro-EDM) ile delinmesi incelenmiştir. Mikro-EDM işleminde akım (A) (3, 4 ve 5 A), vurum süresi ( $\left.\mathbf{T}_{\text {on }}\right)(3,4$, ve $5 \mu \mathrm{s})$ ve bekleme süresinin ( $\left.\mathbf{T}_{\text {off }}\right)(2$, 3, ve $4 \mu \mathrm{s})$ delik girişindeki deformasyon faktörü $\left(\mathbf{F d}_{\mathbf{T}}\right)$, delik çıkışındaki deformasyon faktörü $\left(\mathbf{F d}_{\mathbf{B}}\right)$ ve Kerf açısına $\left(\boldsymbol{K}^{\circ}\right)$ etkisi araştırılmışıır. Deney düzeni Taguchi metodu $\mathrm{L}_{9}$ ortogonal dizilime göre yapılmıştır. Mikro-EDM işleminde sonuçlara çoklu faktörler etki ettiği için Gri İlişki Analizi (GRA) çoklu karakterizasyon yöntemi kullanılmıştır. $\boldsymbol{K}^{\mathbf{0}}, \mathbf{F d}_{\mathbf{T}}$ ve $\mathbf{F d}_{\mathbf{B}}$ sonuçlarına etki eden en etkili parametrelerin belirlenmesi için varyans analizi (ANOVA) analiz yapılmıştır. Elde edilen sonuçlara göre en düşük $\boldsymbol{K}^{\mathbf{0}}, \mathbf{F d}_{\mathbf{T}}$ ve $\mathbf{F d}_{\mathbf{B}}$ değerleri sırasıyla $0,267^{\circ}-24,259 \mu$ s ve $59,534 \mu$ s olarak tespit edilmiştir. Taguchi Metoduyla tahmin edilen değerlerin $\% 95$ güven aralığında (CI) içinde olduğu görülmüştür. ANOVA analizine göre sonuçlara etki eden en önemli faktör \%99,1 katkı oranı ile Akım olarak belirlenmiştir.

Anahtar Kelimeler: R65 paslanmaz çelik, Mikro EDM, Deformasyon

\section{Evaluation of Micro-Electro Erosion Drilling Capability of 1.2316 Stainless Steel (R65) Using Taguchi Method and Gray Relational Analysis}

\begin{abstract}
In this study, the drilling of R65 stainless steel with Micro-Erosion Machining (Micro-EDM) was investigated. In micro-EDM process, the effects of current (A) $(3,4$ and $5 \mathbf{A})$, pulse duration $\left(\mathbf{T}_{\text {on }}\right)(3,4$ and $5 \mu \mathrm{s})$ and standby time $\left(\mathbf{T}_{\text {off }}\right)(2,3$ and $4 \mu \mathrm{s})$ on deformation factor at hole entrance $\left(\mathbf{F d}_{\mathbf{T}}\right)$ deformation factor at hole exit $\left(\mathbf{F d}_{\mathbf{B}}\right)$ and Kerf angle $\left(\boldsymbol{K}^{\boldsymbol{\sigma}}\right)$ were investigated. The experimental setup was done according to Taguchi method $\mathrm{L}_{9}$ orthogonal array. Gray Relationship Analysis (GRA) multiple characterization method was used in micro-EDM process, as multiple factors affect the results. Analysis of variance (ANOVA) was performed to determine the most effective parameters affecting $\boldsymbol{K}^{\boldsymbol{o}}, \mathbf{F} \mathbf{d}_{\mathbf{T}}$ and $\mathbf{F} \mathbf{d}_{\mathbf{B}}$ results. According to the results obtained, the lowest $\boldsymbol{K}^{\boldsymbol{o}}$, $\mathbf{F d}_{\mathbf{T}}$ and $\mathbf{F d}_{\mathbf{B}}$ values were determined as $0.267^{\circ}, 24.259 \mu \mathrm{s}$ and $59.534 \mu \mathrm{s}$, respectively. It was seen that the values estimated by the Taguchi Method were within the $95 \%$ confidence interval (CI). According to the ANOVA analysis, the most important factor affecting the results was determined as current with a $99.1 \%$ contribution rate.
\end{abstract}

Keywords: R65 stainless steel, Micro EDM, Deformation

Geliş: 30/11/2020, Düzeltme: 26/12/2020, Kabul: 26/12/2020 


\section{GIRIS}

Son yıllarda, işlenmesi zor malzemelerin delinmesi ile ilgili çalışmalar literatürde önemli yer tutmaktadır. Bu malzemeler mükemmel mekanik özelliklere sahip olduklarından verimli şekilde işlenmesi kapsamlı bir şekilde kullanmasını sağlayabilir. Elektro erozyon işleme (EDM), işlenmesi zor olan iletken malzemelerin etkili ve ekonomik bir şekilde işlenmesi için kullanılan geleneksel olmayan bir talaş kaldırma yöntemidir [1]. Ayrıca küçük ölçekli formların oluşturulması ve deliklerin delinmesinde de kullanılmaktadır.

Küçük deliklerin delinmesi birçok makine ve ekipmanın üretiminde karşılaşılan sorunlardan biri düşük delik çapı/delik boyu oranıdır [2]. Küçük çaplı deliklerin delinebilmesi için yüksek maliyetli teknolojik cihazların kullanılması gereklidir. Mikro delik delmek için lazer işleme ve mekanik delik delme gibi yöntemler kullanılır. Lazerle derin delme işleminde delik ovaliteleri (dairesellik) yüksek çıkmaktadır. Ayrıca yüksek elektrik sarfiyatından dolayı bu işlemin maliyeti yüksektir. Geleneksel yöntemlerde ise küçük çaplı matkap sarfiyat maliyetleri yüksektir. Fakat mikro-EDM cihazı ile mikro deliklerin delinmesi düşük maliyetle çözülebilmektedir [3]. Mikro-EDM işlem özellikleri, makro işleme özelliklerine çok benzemektedir. EDM işparçasının yüzeyine elektrot ile 1sı sağlayarak meydana gelen noktasal bir erime ve buharlaşmayla işparçasından parça koparma işlemidir. EDM işleminde dielektrik sıvı, kısmen iyonize edilmiş bir gaz kanalı oluşturur. Böylece kesme işlemi oluşur. Mikro- EDM işleminin avantajlarının yanında bazı zorlukları da vardır. Mikro delme işleminde elektrot küçük olduğu için boşalım yerinden ısıyı uzaklaştırmak için yeterli alana sahip değildir. Bu, tek bir vurum sağlanabilecek enerji miktarını ve dolayısıyla İşparçası İşleme Hızını (ïH) sınırlar [4]. EDM'de talaş kaldırma mekanizmasının elektrik enerjisi transferine ve termal sürece dayandığı bilinmektedir. Bununla birlikte, elektrik enerjisinden termal enerjiye enerji transferi, özellikle küçük enerji $(<100 \mu \mathrm{J})$ kullanan mikro-EDM 'de hala çalışılan bir konudur [5]. Mikro-EDM işlemindeki bu tür zorlukların giderilmesi için birçok araştırmacı Mikro-EDM 'de bilinmeyen faktörlerin işleme performansına etkisini belirlemek için araştırmalar yapmaktadır. Yapılan deneysel çalışmaların uzun sürmesi ve maliyetli olması nedeniyle optimizasyon yöntemleri kullanılmaktadır. Bu yöntemlerden biri olan Taguchi Metodu bu tür mühendislik uygulamalarında deney tasarımı yaparak parametrelerin optimizasyonunda yaygın olarak kullanılmaktadır [6]. Özellikle maliyeti yüksek deneylerde deney sayısını azaltarak güvenilir sonuçlar elde edilmesini sağlamaktadır. Son yıllarda çoklu faktörün bulunduğu deneylerde Taguchi temelli GRA yardımıyla faktörlerin çoklu karakterizasyonu ile daha kapsamlı sonuçlara ulaşılmaktadır [7]. Mühendislik uygulamalarında çoklu performans kriterlerinin optimizasyonu önemli bir konudur. Birçok alternatif arasından en iyisini belirlemek oldukça zordur. Mevcut alternatifleri birden çok kritere göre değerlendirerek aralarından en iyi olan kriteri tespit etme işlemi Çok Kriterli Karar Verme (ÇKKV) problemi olarak ortaya çıkmaktadır. Yetersiz veya belirsiz verilerin bulunduğu durumlarda derecelendirme, sınıflandırma ve karar verme tekniği olan ÇKKV yöntemleri kullanılmaktadır. GRA yöntemi de bu yöntemlerden biridir [8]. GRA yöntemi Taguchi Metoduyla birlikte kullanılmaktadır. Örneğin Natarajan ve ark. [9] çoklu performans karakteristik optimizasyonu ile Mikro-EDM işleminde, malzeme aşınma oranı, elektrot aşınma oranı ve kesme boşluğu (overcut) karakteristiklerini değerlendirmişlerdir. Optimizasyon işlemi ve sonuçların değerlendirilmesi için Taguchi Metodu ve GRA kullanmışlardır. Deneysel parametre olarak vurum süresi, akım ve boşluk voltajını kullanmışlardır. Yapmış oldukları ANOVA analizine göre vurum süresini, malzeme aşınma oranı, elektrot aşınma oranı ve kesme boşluğu sonuçlarına katkıda bulunan en etkili parametre olarak tespit etmişlerdir. Ay ve ark. [10] çoklu performans özelliklerine sahip Inconel 718 nikel bazlı süper alaşımın Mikro-EDM delme işlemini optimize etmek için GRA yöntemini kullanmışlardır. Akım ve vurum süresi parametrelerinin işleme performansına etkisini belirlemek için deneyler gerçekleştirmişlerdir. Delik koniklik oranı ve dairesellik sonuçlarını değerlendirmişlerdir. Optimizasyon metodu ile elde ettikleri sonuçlara göre akımın vurum süresine göre işleme delik koniklik oranı ve dairesellik sonuçlarında daha etkili olduğu sonucuna ulaşmışlardır. Farklı bir çalışmada Mohanty ve ark. [11] Mikro-EDM işleminde Inconel 825 süper alaşımın talaş kaldırma oranı, yüzey pürüzlülüğü, radyal kesme boşluğu, ve yüzey kırılma yoğunluğu sonuçlarını optimize etmişlerdir. Deney tasarımını Taguchi $\mathrm{L}_{9}$ ortogonal dizilime göre yapmışlardır. EDM birden fazla performans özelliği içerdiğinden, Inconel 825'in EDM işlemi sırasında işlem parametrelerini 
optimize etmek için çok amaçlı optimizasyon tekniği olan GRA'yı kullanmışlardır. Analiz sonucunda, işlem parametrelerinin ideal kombinasyonunu akım $(1 \mathrm{~A})$, vurum süresi $(10 \mu \mathrm{s})$ ve görev faktörü (\%75) olarak tespit etmişlerdir. Tsai ve ark. [5] çalışmasında, elektrotun şekil değişikliği ve aşınmasını, taramalı elektron mikroskobu (SEM) görüntülerini kullanarak değerlendirmişlerdir. $\mathrm{Bu}$ araştırmayla EDM işleminde önemli maliyet sorunu olan elektrot sarfiyatını azaltmayı amaçlamışlardır. Bu amaçla, termal özelliklerin elektrot aşınması üzerindeki etkileri araştırmışlardır. Deneylerde kullanılan bakır elektrotun kaynama noktası, erime noktası ve ısıl iletkenliği yükseldikçe elektrotun aşınma oranının azaldığını tespit etmişlerdir. Chern ve ark. [12] $200 \mu \mathrm{m}$ çapında mikro delikler delebilmek amaciyla titreşimli EDM işlemi yapan özel makine geliştirmişlerdir. Geliştirdikleri makinede otomatik besleme sistemini kullanarak SUS304 paslanmaz çelik ve pirinç işparçasına toplu olarak mikro deliklerin delinmesini başarıyla gerçekleştirmişlerdir. Masuzawa ve ark. [13] derin mikro deliklerin EDM ile işlenmesi üzerine deneysel bir çalışma yapmışlardır. Deneylerde dielektrik olarak su kullanan yatay bir EDM kullanmışlardır. Yatay EDM işlemi ile $50 \mu \mathrm{m}$ çapında ve çapın yaklaşık on katı derinliğe sahip mikro deliklerin delilenebildiğini göstermişlerdir. Yan ve ark. [14] çalışmalarında, bakır elektrot kullanarak EDM ile karbürün mikro delik özelliklerini araştırmışlardır. Karbür işparçasına yüksek hassasiyetli mikro delme işleminde, elektrot dönme hızının deformasyon oluşumu, elektrot aşınma oranı, elektrot aşınmasına etkilerini incelemişlerdir. Karbürün EDM işleminde bakır elektrot ile mikro delikler delinmesinde, pozitif kutuplu işlemin gerekli olduğunu tespit etmişlerdir. Ayrıca elektrotun dönme hızının arttırılmasının, çapak tahliyesini iyileştirdiği ve mikro deliğin genişlemesini azalttığı sonucuna ulaşmışlardır. Tang ve ark. [15] S-03 paslanmaz çeliğin hassas EDM işleme parametrelerini optimize etmek için GRA ve Taguchi $\mathrm{L}_{9}$ ortogonal deneysel yöntemi birleştirmeyi amaçlamışlardır. Deney parametresi olarak akımı $7 \mathrm{~A}$, vurum aralığ $100 \mu \mathrm{s}$, vurum genişliği $50 \mu \mathrm{s}$ ve boşluk voltajı $70 \mathrm{~V}$ kullanmışlardır. Sonuçlar, Taguchi Metodu ve GRA birleştirilmesinin işleme parametrelerini daha iyi optimize edebileceğini ve İIH'nin \% 23,8 arttığını göstermişlerdir. Elde edilen ideal şartlarda en iyi yüzey pürüzlülüğü $1,7 \mu \mathrm{m}$ ve $\dot{I} H \mathrm{H} 13,3 \mathrm{~mm}^{3} / \mathrm{dak}$ olarak tespit etmişlerdir. Sarıkaya ve ark. [16] AISI 304 paslanmaz çeliğin mikro EDM yöntemi ile delinebilmesini araştırmışlardır. Boşalım akımı, dielektrik püskürtme basıncı ve elektrot dönüş hızı gibi test parametrelerinin İHH, elektrot aşınma oranı (TWR), ortalama aşırı kesme (AOC) ve konik açına etkisini araştırmışlardır. İdeal işlem parametrelerini sırasıyla tekli optimizasyon ve çoklu yanıt optimizasyonu için sinyal-gürültü $(\mathrm{S} / \mathrm{N})$ analizi ve yanıt yüzey metodolojisi (RSM) kullanarak belirlemişlerdir. Çok amaçlı optimizasyon yardımıyla ideal işleme parametrelerini; boşalım akımı 10,18 A, dielektrik sıvı basınc1 58,78 bar ve elektrot dönüş hızı $100 \mathrm{rpm}$ olarak belirlemişlerdir. ANOVA yardımıyla işleme hızı, elektrot aşınma oranı ve koniklik açısını etkileyen en önemli faktörün akım olduğunu belirlemişlerdir. Wang ve ark. [17] Mikro-EDM ile Polikristalin elmas (PCD)'lerin mikro delik işleme performansını araştırdı. Deneysel sonuçlar, negatif polarite işlemenin, elektroda yapışan malzemenin getirdiği koruma nedeniyle PCD'lerin mikro EDM'si için uygun olduğunu göstermiştir. Elektrotun uygun bir yapışma hacmi, (IIIH) artırmaya ve TWR azaltmaya yardımcı olabileceği sonucuna ulaşmışlardır. Erdem ve ark. [18] EDM delik delme işleminde yüzey kalitesini arttırmak için kendi etrafında dönen ortası delik pirinç elektrotlar kullanmışlardır. Çalışmalarında hidrokarbon bazlı dielektrikler yerine karbon ve nişasta tozu katkılı 1sıttılmış silikon yağını kullanılmışlardır. Karbon tozu katkılı silikon yağı karışımıyla elde edilen dielektrikler sayesinde oldukça yüksek İ̈H'ye ulaşmışlardır. Deneylerde kullanılan $30^{\circ} \mathrm{C}$ ve $75^{\circ} \mathrm{C}$ 'lerdeki karbon tozu katkılı dielektriğe nişasta tozu katkısı sayesinde yüzey özelliklerinin iyileştiğini tespit etmişlerdir. Kadirvel ve Hariharan [8] mikro EDM işleminde yüksek IIIH, düşük TWR ve iyi yüzey pürüzlülüğü elde etmek için Taguchi metodu ve Gri İlişki Analizini kullanmışlarıdır. İşleme performansına etki eden direnç, voltaj, ilerleme hızı gibi faktörlerin etkisini araştırmışlardır. Sonuçlara etki eden en etkili faktörün tespiti için ANOVA analizini kullanmışlardır. Sonuçlara etki eden en önemli faktörün voltaj ve direnç olduğu sonucuna ulaşmışlardır. Maity ve Singh [19] bakır malzemenin tungsten elektrot kullanılarak delinen mikro-EDM deliklerin performansını araştırmışlardır. Delik performansını gösteren dairesellik hatası, katman oluşumu ve işleme süresini optimize etmek için Taguchi metodu ve GRA kullanmışlardır. Delme performansına etki eden direnç, voltaj, dönme hızı ve ilerleme hızı parametrelerinin optimizasyonu için Taguchi $\mathrm{L}_{9}$ deney dizilimini kullanmışlardır. Düşük işleme süresi için direnç $0,1 \mu \mathrm{F}$, elektrot ilerleme hızı $0,003 \mu \mathrm{m} / \mathrm{s}$, dönme hızı $1500 \mathrm{rpm}$ ve voltaj1 $90 \mathrm{~V}$ olarak tespit etmişlerdir. Mikro-EDM işleminde, GRA-Taguchi analizi sonuçlarına göre için optimize edilmiş işleme süresini, dairesellik hatasını ve katman kalınlığını en aza indirmek için ideal parametreler 
elektrot ilerleme hızı $0,001 \mu \mathrm{m} / \mathrm{s}$, dönme hızı $1500 \mathrm{rpm}$ ve voltaj $120 \mathrm{~V}$ ve direnç $0,1 \mu \mathrm{F}$ olarak tespit etmişlerdir. Sonuçlar tek başına değerlendirildiğinde en düşük işleme süresi sonuçları için ilerleme hızı ve voltaj değerlerini farklı bulunmuştur. Tüm sonuçlar GRA'ya göre değerlendirildiğinde farklı parametreler ideal değer olarak tespit etmişlerdir. Bu durum, Taguchi temelli Gri ilişkisel analizinin delik delme işlemi gibi performansı etkileyen çoklu karar verme analizlerinde önemini ortaya koymaktadır. Mikro-EDM işlemiyle ilgili literatür çalışmaları değerlendirildiğinde; Mikro EDM işlemiyle ilgili derin mikro deliklerin delinmesinde tam anlamıla sorunların çözüme kavuşturulamadığı görülmektedir. Delik çapları küçüldükçe yüzey deformasyonu artmaktadır. Delik boyu artıkça delik giriş ve çıkış çaplarındaki farktan dolayı kerf açısının oluşumu kaçınılmazdır. Kerf açısının oluşumunu azaltmak için çalışmalar yapılmaya devam etmektedir. EDM işlemlerinde her malzemenin tribolojik ve mekanik özelliğine göre sonuçları etkileyen parametreler değiştiği için ideal şartların belirlenmesi hem işparçası kalitesinin arttırılması hem de işleme maliyetlerinin azaltılması için gereklidir. Taguchi Metodu gibi optimizasyon yöntemleri deney sayılarını azaltarak hem zaman hem de deney maliyetlerinde tasarruf sağlamaktadır. Yapılan çalışmalar ile çoklu parametrelerin etki ettiği EDM işlemlerinde deney tasarımları Taguchi Metodu ve GRA kullanılarak başarılı bir şekilde yapılarak güvenilir deney sonuçları elde edilmiştir. Piyasada yaygın olarak kullanılan R65 paslanmaz çelikle ilgili mikro delik çalışmaları sınırlıdır. Bu nedenle bu malzemenin Mikro-EDM delik performansının değerlendirilmesi faydalı olacaktır.

Bu çalışmada R65 çeliğin Mikro-EDM ile delinmesi incelenmiştir. Akım, vurum süresi ve bekleme süresi faktörlerinin, deformasyon faktörü ve kerf açısına etkisi araştırılmıştır. Mikroskop ile deformasyon oluşumu incelenmiştir. Deneyler Taguchi metodu $\mathrm{L}_{9}$ ortogonal dizilime göre yapılmıştır. Mikro-EDM işleminde sonuçlara çoklu faktörler etki ettiği için GRA çoklu karakterizasyon yöntemi kullanılmıştır. Sonuçlara etki eden en önemli faktörü ve etki oranının tespiti için ANOVA analizi yapılmıştır.

\section{MATERYAL METOT}

Deneysel çalışmada, 20x30x10 mm boyutlarında R65 paslanmaz çelik kullanılmıştır. 1,2316 paslanmaz çelik (R65) yüksek krom içeriği nedeniyle iyi korozyon dayanıma sahip paslanmaz çeliktir. 27- 33 Rockwell C (RC)'ye ön sertleştirilmiş plastik kalıp çeliğidir. İçeriğindeki kükürt sayesinde hızlı işlenebilme özelliğine sahiptir. Bu özellikleri nedeniyle PVC korozif plastiklerin ve polimerlerin büyük kalıplarında kullanılırlar. Ayrıca gıda endüstrisine yönelik bıçak, kalıp ve diğer parçaların yapımında da kullanılırlar. Krom veya nikel kaplamaya gerek kalmadan kullanılması malzemeye avantaj sağlamaktadır. Alevle sertleştirmeye, nitrasyona ve indüksiyona uygundur. Manyetik özelliği ve parlatma özelliği iyidir.

Deneyler, Bohong Machinery marka EDM delme tezgâhında gerçekleştirilmiştir. Deney düzeneği ( Şekil 1)'de verilmiştir. Deneylerde dış çapı $0,3 \mathrm{~mm}$ iç çapı $0,15 \mathrm{~mm}$ olan $500 \mathrm{~mm}$ boyunda pirinç elektrot kullanılmıştır. Numuneler boydan boya delinmiştir $(10 \mathrm{~mm})$. EDM tezgâhında Voltaj $100 \mathrm{~V}$, elektrot devir sayıs1 $1000 \mathrm{rpm}$ elektrot ilerleme hizı $0,002 \mu \mathrm{m}$ olark belirlenip bu parametreler sabit tutulmuştur. Dielektrik sıvısı olarak EDM ULTRA marka üstün oksidasyon stabilitesine ve parlama noktasına sahip, düşük viskoziteli sıvı kullanılmıştır. Dielektrik püskürtme basıncı 40 bar olarak belirlenmiştir. Deneylerde kullanılan EDM Bohong Machinery tezgâhının teknik özellikleri Tablo 1 'de verilmiştir. 


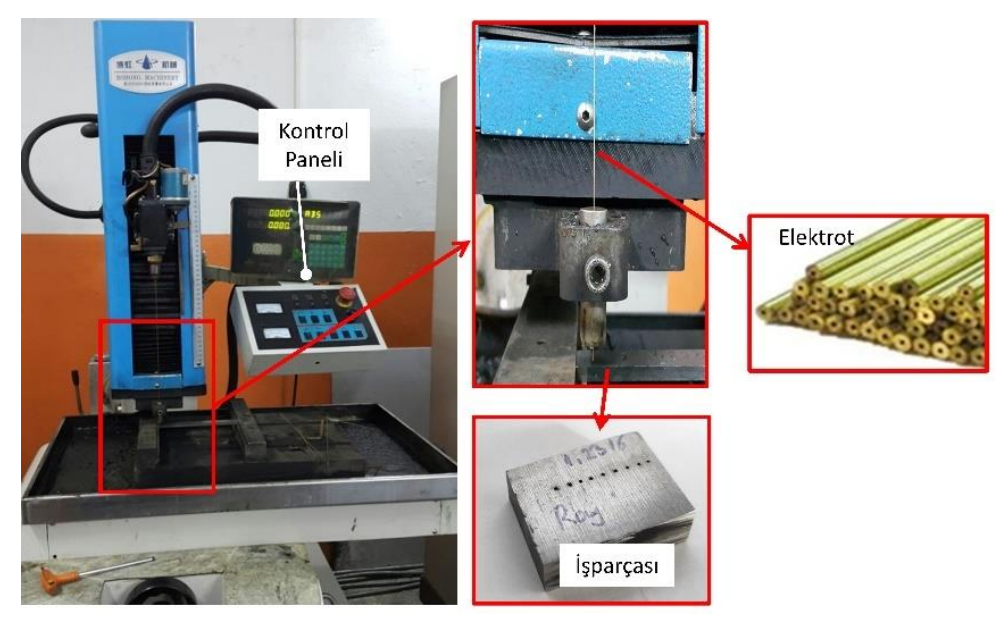

Şekil 1. Deneysel çalışmada kullanılan EDM delik delme tezgâhı ve bileşenlerinin görüntüsü

Tablo 1. Bohong Machinery marka EDM tezgâhı Teknik özellikleri

\begin{tabular}{rrr}
\hline Model/özellikler & \multicolumn{2}{c}{ DK703 Birim } \\
\hline Tabla & $320 \times 440$ & $\mathrm{~mm}$ \\
Tabla hareketi & $250 \times 350$ & $\mathrm{~mm}$ \\
İşleme akımı & 30 & $\mathrm{~A}$ \\
Elektrot çapı & $\varnothing 0,3-\varnothing 3,0$ & $\mathrm{~mm}$ \\
Tabla yükü & 200 & $\mathrm{Kg}$ \\
Çalışma sıvısı & EDM ULTRA Dielektrik sıvis1 & - \\
Güç & $380 \mathrm{~V} / 50 \mathrm{HZ}$ & $/$ \\
Güç tüketimi & $3,5 \mathrm{KVA}$ \\
\hline
\end{tabular}

Talaş kaldırma işleminin yapılabilmesi için, işparçası ile elektrot arasında bir bağlantının bulunması ve güç kaynağının devamlı elektrik akımı üretmesi gerekmektedir. EDM delik delme işlemi ve deformasyon işleminin tanımlamasını anlatan görsel

Şekil 2'de verilmiştir. 


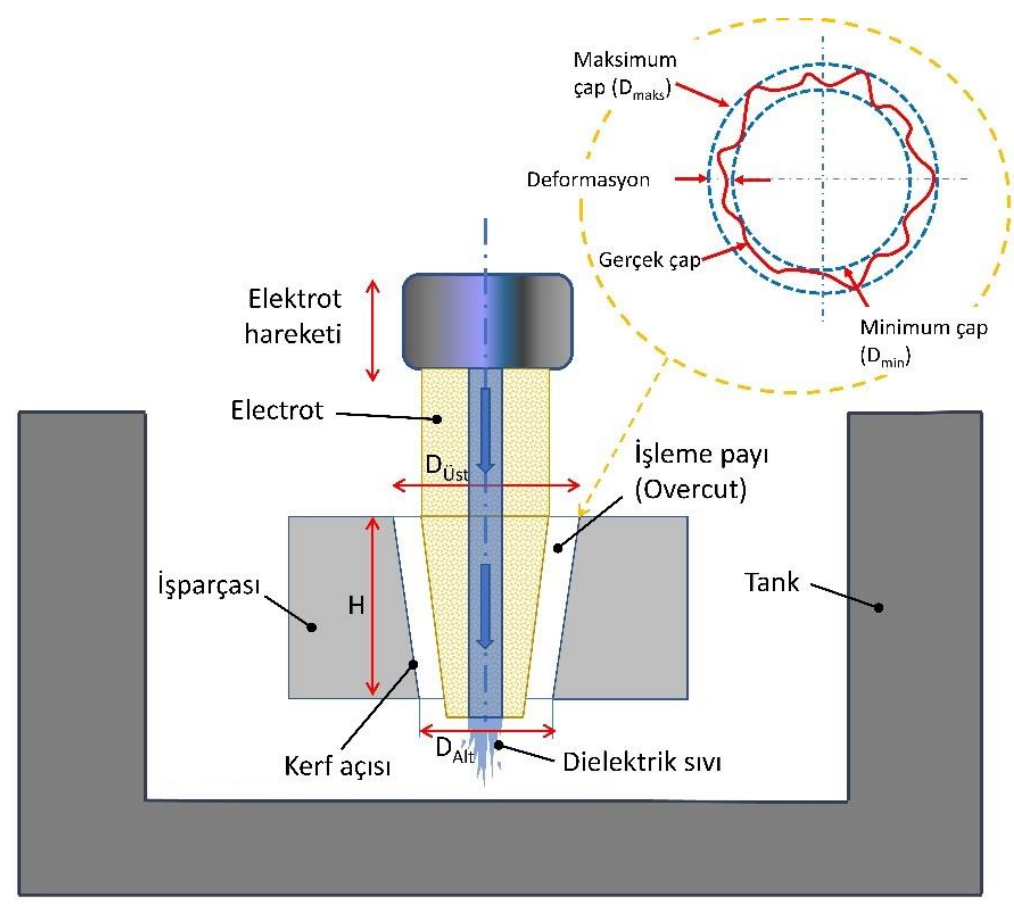

Şekil 2. EDM delik delme işlemi ve deformasyon

Mikro delik ile işlemede deliğin ortalama çapı $\left(\mathrm{D}_{\text {ort }}\right)$ Eşitlik 1 ile koniklik açısı ise Eşitlik 2 ile hesaplanmaktadır. Delik giriş çapı $\left(\mathrm{D}_{\mathrm{T}}\right)$, delik çıkış çapı $\left(\mathrm{D}_{\mathrm{B}}\right)$ Kerf açısı $\left(\boldsymbol{K}^{\mathbf{0}}\right)$ açısı ve $\mathrm{H}$ işparçası malzemesinin kalınlığını ifade etmektedir [20].

$\mathrm{D}_{\text {ort }}=\frac{\mathrm{D}_{\mathrm{T}}+\mathrm{D}_{\mathrm{B}}}{2}$

$K=\arctan \frac{\mathrm{D}_{\mathrm{T}}-\mathrm{D}_{B}}{2 \mathrm{H}}$

Deformasyon faktörü Eşitlik 3'e göre hesaplanır.

$\mathrm{Fd}=\mathrm{D}_{\text {maks }}-\mathrm{D}_{\text {min }}$

Burada Fd deformasyon faktörü, $\mathrm{D}_{\text {maks }}$ maksimum çap, $\mathrm{D}_{\min }$ minimum çapı, $\left(\mathbf{F d}_{\mathbf{T}}\right)$ delik girişindeki deformasyon faktörünü, $\left(\mathbf{F d}_{\mathbf{B}}\right)$ delik çıkışındaki deformasyon faktörünü ifade etmektedir Deneylerde elde edilen delik görüntüleri dijital mikroskop ile görüntülenmiştir. Image J görüntü analiz programı ile delik giriş ve çıkış görüntüleri analiz edilmiştir.

$\mathrm{Bu}$ çalışmada deney tasarımı Taguchi $\mathrm{L}_{9}$ deney dizilimine göre Minitab 17 programı kullanılarak yapılmıştır. EDM delme işleminde kalite özelikleri üzerinde önemli etkileri olduğu düşünülen kontrol parametreleri tanımlanır. Kontrol parametreleri ayarlanabilen ve korunabilen tasarım faktörleridir. Her test parametresi için seviyeler (test değerleri) bu noktada belirlenir. Deneysel çalışmada kullanılan parametreler (akım, vurum süresi, bekleme süresi) ve seviyeleri Tablo 2'te gösterilmiştir. Deney tasarımında faktör ve seviyelere uygun olan Taguchi metodu $\mathrm{L}_{9}$ deney dizilimi seçilmiştir (Tablo 3).

Tablo 2. Deney faktör ve seviyeleri

\begin{tabular}{rrrrrrr}
\hline & Faktör & Semboller & Birim & Seviye 1 & Seviye 2 & Seviye 3 \\
\hline $\mathbf{1}$ & Akım & $\mathrm{A}$ & $\mathrm{A}$ & 3 & 4 & 5 \\
$\mathbf{2}$ & Vurum süresi & $\mathrm{B}$ & $\mu \mathrm{s}$ & 3 & 4 & 5 \\
$\mathbf{3}$ & Bekleme süresi & $\mathrm{C}$ & $\mu \mathrm{s}$ & 2 & 3 & 4 \\
\hline
\end{tabular}


Tablo 3. Taguchi $L_{9}$ ortogonal deney düzeni

\begin{tabular}{rrrr}
\hline No & Faktör A & Faktör B & Faktör C \\
\hline 1 & 1 & 1 & 1 \\
2 & 1 & 2 & 2 \\
3 & 1 & 3 & 3 \\
4 & 2 & 1 & 2 \\
5 & 2 & 2 & 3 \\
6 & 2 & 3 & 1 \\
7 & 3 & 1 & 3 \\
8 & 3 & 2 & 1 \\
9 & 3 & 3 & 2 \\
\hline
\end{tabular}

S/N oranı, standart sapma yerine ölçülebilir bir değer olarak kullanılır. Taguchi tarafindan geliştirilen $\mathrm{S} / \mathrm{N}$ oranı, gürültü ile en iyi şekilde başa çıkabilecek kontrol seviyelerini seçmek için bir performans ölçüsüdür. $\mathrm{S} / \mathrm{N}$ oranı hem ortalamayı hem de değişkenliği hesaba katar. En basit hali ile $\mathrm{S} / \mathrm{N}$ oranı, ortalamanın (sinyal) standart sapmaya (gürültü) oranıdır. S/N oranı özelikleri üç kategoriye ayrılabilir: en küçük en iyi, en büyük en iyi ve nominal değer en iyi. Bunlar içerisinden deformasyon faktörü ve kerf açıs1 için en küçük değerler ideal olduğu için "en küçük en iyi” karakteristiği kullanılmıştır. "En düşük en iyi” karakteristiği Eşitlik 4'e göre hesaplanır.

$\frac{S}{N}:-10 \log \left(\frac{1}{n} \sum_{i: 1}^{n} y_{i}^{2}\right)$

Burada $\eta$ test sayısı, $y_{i} i$ 'inci kalite karakteristiğinin deneysel değeridir.

Bu çalışmada Taguchi temelli GRA analizi kullanılarak çoklu performans faktörlerinin optimizasyonu yapılmıştır. Sonuçları analiz etmek için, Taguchi metodu sinyal-gürültü $(\mathrm{S} / \mathrm{N})$ oranı olarak bilinen performans ölçütü kullanılmıştır.

\section{DENEYSEL SONUCLAR VE TARTISMA}

Deneysel çalışmada gerçekleştirilen mikro delik delme işleminde elde edilen delik girişindeki deformasyon faktörü $\left(\mathbf{F d}_{\mathbf{T}}\right)$, delik çıkışındaki deformasyon faktörü $\left(\mathbf{F d}_{\mathbf{B}}\right)$ ve $\operatorname{Kerf}$ açısı $\left(\boldsymbol{K}^{\mathbf{0}}\right)$ sonuçları Tablo 4' de verilmiştir.

Tablo 4. Mikro deliklerin delinmesinden elde edilen sonuçlar

\begin{tabular}{|c|c|c|c|c|c|c|c|c|c|}
\hline $\begin{array}{r}\text { Deney } \\
\text { No }\end{array}$ & $\begin{array}{r}\text { Akım } \\
\text { (A) }\end{array}$ & $\begin{array}{r}T_{\text {on }} \\
(\boldsymbol{\mu s})\end{array}$ & $\begin{array}{r}T_{\text {off }} \\
(\mu \mathrm{s})\end{array}$ & $\begin{array}{c}\text { Giriş } \\
\text { çapi } \\
(\mu \mathrm{s})\end{array}$ & $\begin{array}{r}\text { Çıkış çapı } \\
(\mu \mathrm{s})\end{array}$ & $\begin{array}{r}\text { Deformasyon } \\
\text { faktörü }\end{array}$ & $\begin{array}{r}\text { Kerf } \\
\text { AçıS1 } \\
\left(K^{0}\right)\end{array}$ & $\begin{array}{r}\text { Giriş } \\
\text { Deformasyon } \\
\text { Faktörü } \\
\left(\mathbf{F d}_{\mathrm{T}}\right) \\
\end{array}$ & $\begin{array}{r}\text { Çıkış } \\
\text { Deformasyon } \\
\text { Faktörü } \\
\left(\mathbf{F d}_{\mathbf{B}}\right) \\
\end{array}$ \\
\hline 1 & 1 & 1 & 1 & 330,374 & 251,395 & 1,314 & 1,323 & 24,259 & 59,534 \\
\hline 2 & 1 & 2 & 2 & 315,263 & 292,977 & 1,076 & 0,839 & 33,054 & 77,921 \\
\hline 3 & 1 & 3 & 3 & 331,401 & 304,147 & 1,090 & 0,938 & 50,514 & 64,058 \\
\hline 4 & 2 & 1 & 2 & 322,375 & 316,899 & 1,017 & 0,267 & 52,329 & 75,652 \\
\hline 5 & 2 & 2 & 3 & 343,963 & 274,378 & 1,254 & 1,291 & 32,601 & 124,752 \\
\hline 6 & 2 & 3 & 1 & 342,915 & 297,104 & 1,154 & 1,159 & 38,195 & 111,594 \\
\hline 7 & 3 & 1 & 3 & 348,853 & 290,363 & 1,201 & 1,241 & 54,849 & 135,545 \\
\hline 8 & 3 & 2 & 1 & 338,482 & 302,472 & 1,119 & 1,064 & 40,604 & 169,239 \\
\hline 9 & 3 & 3 & 2 & 334,422 & 306,643 & 1,091 & 0,947 & 55,404 & 140,045 \\
\hline
\end{tabular}


Elde edilen sonuçlara göre en düşük kerf açısı 4. Deneyde 0,267 $\boldsymbol{K}^{\mathbf{0}}$ olarak tespit edilmiştir. $\mathbf{F d}_{\mathbf{T}}$ ve $\mathbf{F d}_{\mathbf{B}}$ ise en düşük değer 1. deneyde sırasıyla 24,259 ve 59,534 olarak tespit edilmiştir. Giriş delikleri genellikle çıkış deliklerinden daha büyük çıkmıştır. Bu durum elektrotun delik sonuna doğru aşınmasından kaynaklandığı söylenebilir. $\mathbf{F d}_{\mathbf{B}}$ değerleri akımın artmasıyla yükselmiştir. Bu durum da akımın yükselmesi delik çıkışındaki deformasyonun arttığını göstermektedir. Delme işlemi gerçekleştirilen malzemenin delik giriş ve çıkışlarının optik görüntüsü

Şekil 3' de gösterilmektedir. Deliklerin giriş ve çıkışlarının mikroskop görüntüleri incelendiğinde parametrelere göre delik deformasyonunun farklı olduğu görülmektedir. Delik çıkışlarındaki deformasyonun delik girişlerine göre daha belirgin olduğu görülmektedir. Akım şiddeti arttıç̧a delik çıkışlarında deformasyon daha belirgindir. En yüksek akımın olduğu (5 Amper) 7, 8 ve 9 nolu deneylerde bu durum açı şekilde görülmektedir. Deformasyonla birlikte bu deliklerde çapaklanmalar da meydana gelmiştir. Delik giriş ve çıkışlarındaki dairesellik hatası, deformasyon elektrotun dönüşünden ve oluşan titreşimlerden kaynaklandığı söylenebilir. Kadirvel ve ark. [21] kalıp çeliklerinin mikro EDM ile delinmesinde deliklerin yüzey kalitesine ve dairesellik hatalarına elektrotta meydana gelen titreşimlerin sebep olduğunu belirtmişlerdir.

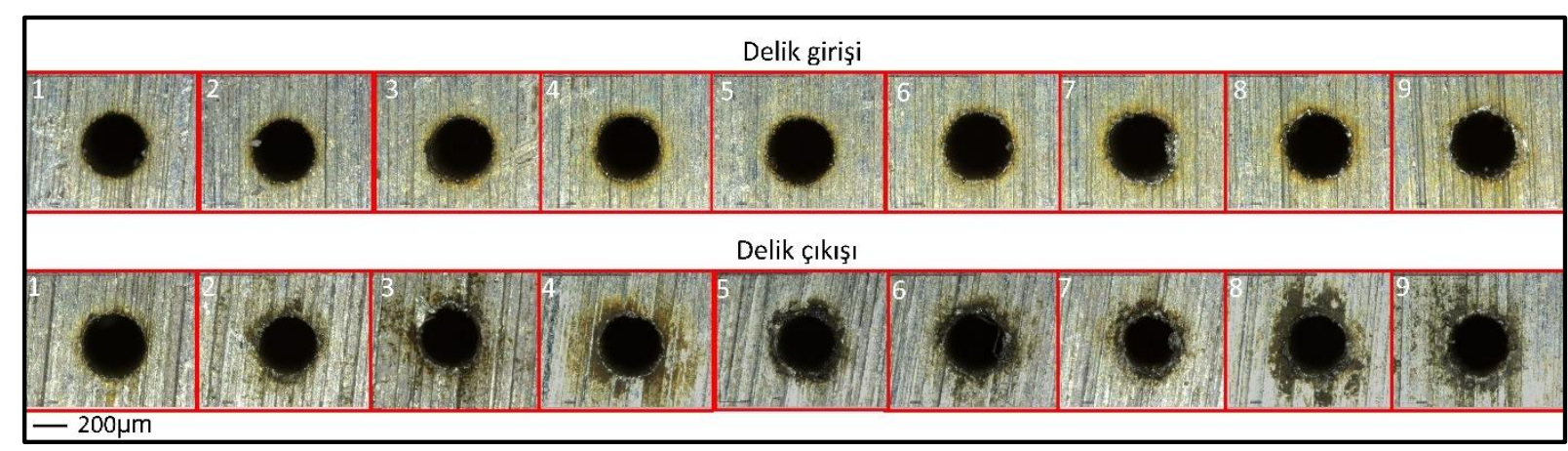

Şekil 3. Delme işlemi gerçekleştirilen R65 paslanmaz çeliğin delik giriş ve delik çıkış görüntüleri

Optimizasyon sonucunda elde edilen en iyi delik ve en kötü delik arasındaki kıyaslama yapmak için görüntüler incelenmiştir. GRA analizi sonucunda elde edilen tüm parametreler için en ideal değer 1 numaralı deneyde elde edilmiştir. En kötü değerler ise 7 numaralı deneyde elde edilmiştir. 1 ve 7 numaralı deneyde elde edilen delik görüntüleri

Şekil 4'te verilmiştir. 1 numaralı delik giriş ve çıkışında deformasyonun az olduğu açık şekilde görülmektedir. 7 numaralı deneyde ise oluşan deformasyon açık şekilde görülmektedir. Delik çıkışında özellikle daha fazla deformasyon oluşmuştur. Bu da artan akımın delik çıkışında deformasyona olumsuz etki ettiği sonucuna varılabilir. Akımın artmasıyla daha yüksek ısılarda erime gerçekleştiği için delik etrafında yanmalar ve cüruf oluşumu dikkat çekmektedir. Pradhan ve ark. [22] titanyum alaşımının mikro EDM işleminde delik giriş ve çıkışlarında benzer deformasyonların oluştuğu sonucuna varmışlardır. $T_{\text {on }}$ arttıkça elektrotun ucunda aşınma meydana geldiğini ve bu aşınmanın delik girişinde deformasyonlara sebep olduğunu belirtmişlerdir. Oluşan deformasyonlar nedeniyle delik çaplarında dairesellik hataları oluştuğunu tespit etmişlerdir. Ayrıca $T_{\text {on }}$ arttıkça delik yan yüzeylerinde de beyaz tabaka oluştuğunu görmüşlerdir. 


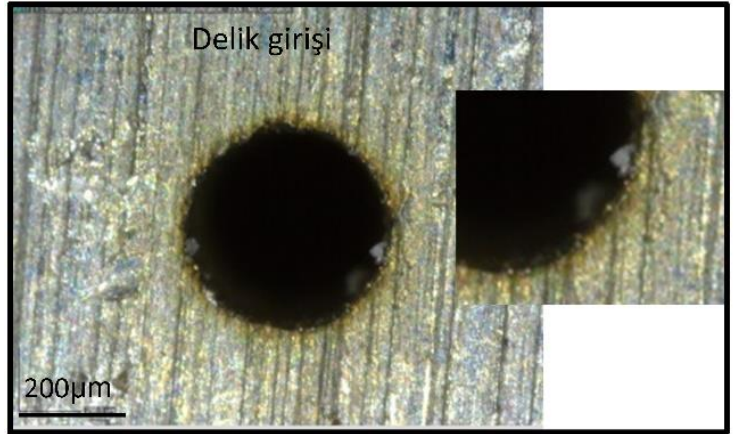

(a)

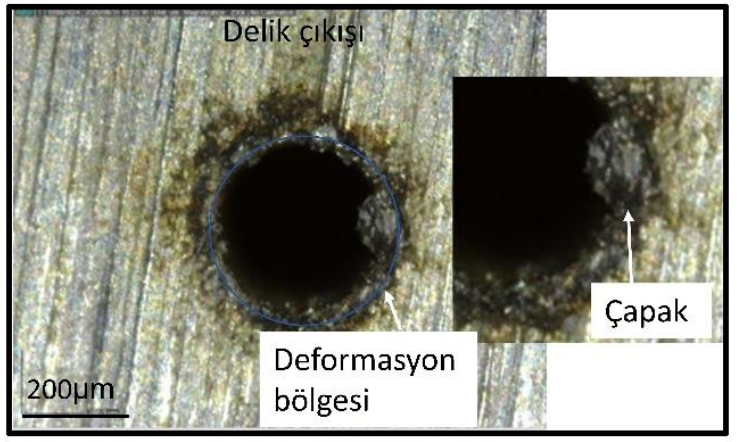

(c)

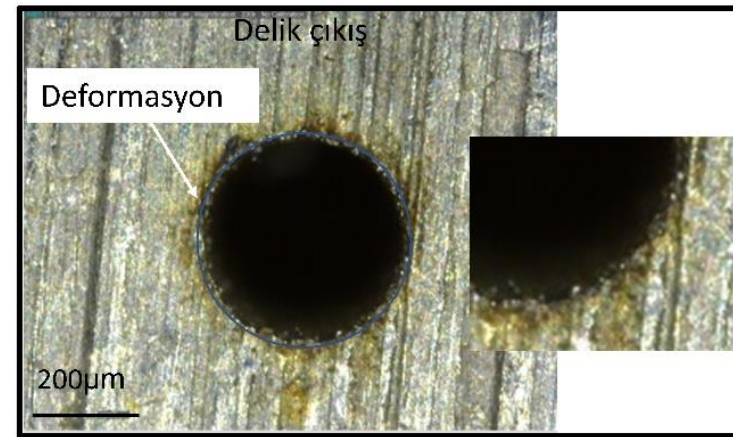

(b)

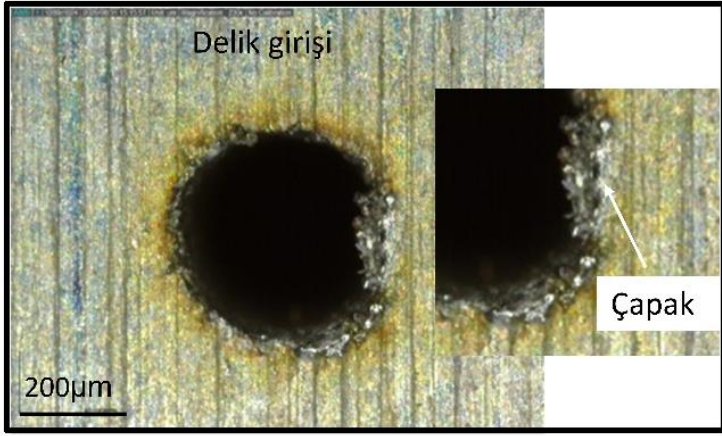

(d)

Şekil 4. Delik mikroskop görüntüleri, a) 1 numaralı delik girişi, b) 1 numaralı delik çıkışı, c) 7 numaralı delik girişi, d) 7 numaralı delik çıkışı

Taguchi metodu kullanılarak gerçekleştirilen analizde $\mathbf{F d}_{\mathbf{T}}, \mathbf{F} \mathbf{d}_{\mathbf{B}}$ ve $\boldsymbol{K}^{\circ}$ için en ideal parametreler için "en küçük en iyi” karakteristiği kullanılmıştır. Analiz sonrasında elde edilen sinyal gürültü oranları Tablo 5' da gösterilmektedir.

Tablo 5. $\boldsymbol{F d}_{T}, \boldsymbol{F d}_{\boldsymbol{B}}$ ve $\boldsymbol{K}^{\circ}$ ortalama değerler ve $S / N$ oranının yanıt tablosu

\begin{tabular}{rrrrrrrrr}
\hline \multicolumn{1}{c}{ Ortalama değerlerin yanıt tablosu } & \multicolumn{3}{c}{ S/N oranı yanıt tablosu } \\
\hline Seviye & $\mathbf{A}$ & $\mathbf{B}$ & $\mathbf{C}$ & Seviye & $\mathbf{A}$ & $\mathbf{B}$ & $\mathbf{C}$ \\
\hline $\mathbf{1}$ & $\mathbf{3 4 , 7 4}$ & $\mathbf{4 5 , 0 2}$ & 49,69 & $\mathbf{1}$ & $\mathbf{- 3 2 , 8 8}$ & $\mathbf{- 3 4 , 8 1}$ & $-36,03$ \\
$\mathbf{2}$ & 48,67 & 53,51 & 48,53 & $\mathbf{2}$ & $-36,20$ & $-37,09$ & $\mathbf{- 3 5 , 6 9}$ \\
$\mathbf{3}$ & 66,58 & 51,46 & $\mathbf{5 1 , 7 8}$ & $\mathbf{3}$ & $-39,12$ & $-36,30$ & $-36,48$ \\
Delta & 31,83 & 8,49 & 3,25 & Delta & 6,24 & 2,28 & 0,79 \\
Rank & 1 & 2 & 3 & Rank & 1 & 2 & 3 \\
\hline
\end{tabular}

Sinyal gürültü oranı tablosunda sıfıra yakın olan değer en etkili parametredir [8]. Bu çalışmada kontrol faktörlerinin koniklik açısı, giriş hasar faktörü, çıkış hasar faktörü ve ortalama çap için en ideal parametreler bütün çıktılarda akım için seviye 1 , vurum süresi için seviye 1 ve bekleme süresi için seviye 2 olarak oluşmuştur $\left(\mathbf{A}_{1} \mathbf{B}_{1} \mathbf{C}_{2}\right)$. Ortalama değerlerin ve $\mathrm{S} / \mathrm{N}$ oranının yanıt tablosunda (Tablo 6) A faktörünün Rank değeri 1'dir. Rank değeri değişkenlerin önem sırasını vermektedir. Bu tablodan sonuçlara etki eden en önemli faktörün akım olduğunu söyleyebiliriz. Delta, ilgili değişkenin azami ve asgari değerleri arasındaki farktır. Delik girişindeki deformasyon faktörü $\left(\mathbf{F} \mathbf{d}_{\mathbf{T}}\right)$, delik çıkışındaki deformasyon faktörü $\left(\mathbf{F d}_{\mathbf{B}}\right)$ ve $\operatorname{Kerf}$ açısı $\left(\boldsymbol{K}^{\circ}\right)$ sinyal gürültü oranının ana etkiler grafiği Şekil 5' de verilmiştir. 


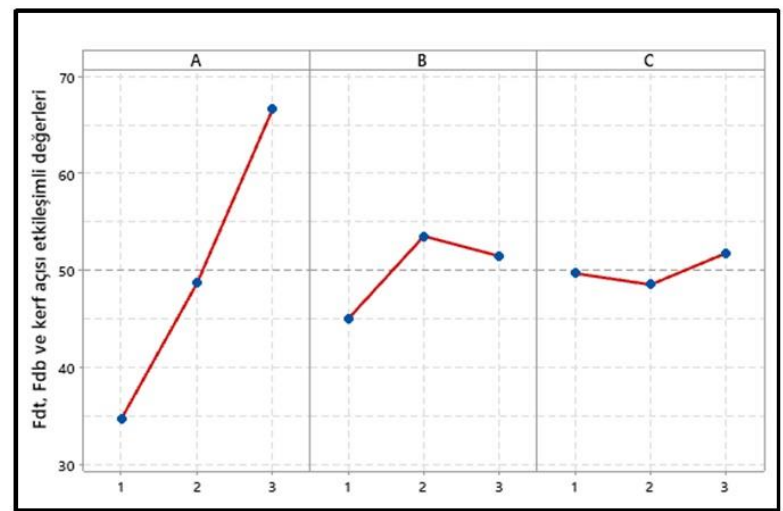

(a)

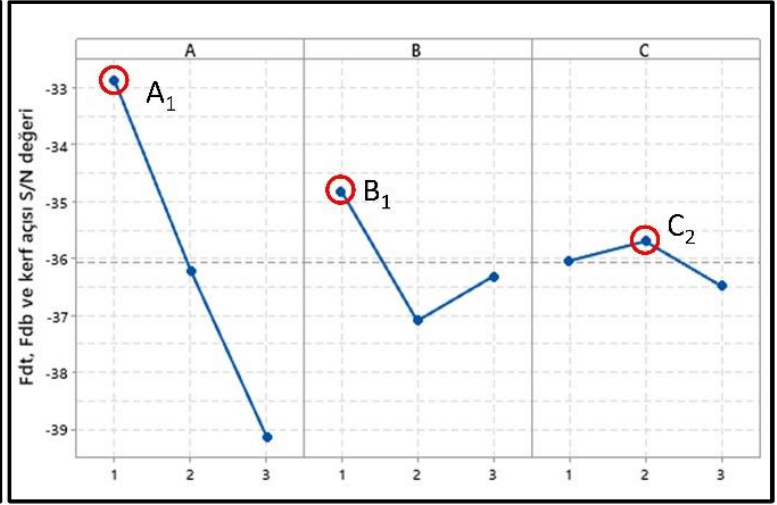

(b)

Şekil 5. $\boldsymbol{F d}_{\boldsymbol{T}}, \boldsymbol{F d}_{\boldsymbol{B}}$ ve $\boldsymbol{K}^{\circ}$ için, a) etkileşimli değerler ve b) $S / N$ oranı grafiği

Delik girişindeki deformasyon faktörü $\left(\mathbf{F} \mathbf{d}_{\mathbf{T}}\right)$, delik çıkışındaki deformasyon faktörü $\left(\mathbf{F d}_{\mathbf{B}}\right)$ ve Kerf açısı $\boldsymbol{K}^{\mathbf{0}}$ 'na ait ANOVA analiz sonuçları Sonuçlarla anlamlı bir ilişkisi olmayan vurum süresi ve bekleme süresinin sırasıyla katkı oranlarının \%7,07 ve \%0,98 olduğu tespit edilmiştir. EDM işleminde akımı arttığında enerji yoğunluğu da artmaktadır. Enerji yoğunluğunun artması deşarj kıvılcımını arttırarak yüksek MRR'ye neden olur [22]. Bu hızlı işleme esnasında aşırı ısınan erimiş malzemeler delik giriş ve çıkışlarına yapışarak çapak oluşumuna sebep olmaktadır. Bu durumda akımın artmasıyla delik girişindeki deformasyon faktörü $\left(\mathbf{F d}_{\mathbf{T}}\right)$, delik çıkışındaki deformasyon faktörünü $\left(\mathbf{F d}_{\mathbf{B}}\right)$ olumsuz etkilemektedir.

Tablo 6'de verilmiştir. $\mathrm{P}<0,05$ olduğunda $\% 95$ güven aralığında $\mathbf{F d}_{\mathbf{T}}, \mathbf{F d}_{\mathbf{B}}$ ve $\boldsymbol{K}^{\circ}$ sonuçları ile akım, vurum süresi ve bekleme süresi arasında istatistiksel açıdan anlamlı bir ilişkinin olduğu sonucu ortaya çıkmaktadır. Sadece akım (A) faktöründe $\mathrm{P}<0,05$ olduğu için $\mathbf{F} \mathbf{d}_{\mathbf{T}}, \mathbf{F} \mathbf{d}_{\mathbf{B}}$ ve $\boldsymbol{K}^{\circ}$ sonuçlarına etki eden tek faktör amper olarak belirlenmiştir. Akımın $\mathbf{F d}_{\mathbf{T}}, \mathbf{F d}_{\mathbf{B}}$ ve $\boldsymbol{K}^{\circ}$ sonuçlarına katkı oranı ise \%99,1 olarak belirlenmiştir. Sonuçlarla anlamlı bir ilişkisi olmayan vurum süresi ve bekleme süresinin sırasıyla katkı oranlarının \%7,07 ve \%0,98 olduğu tespit edilmiştir. EDM işleminde akımı arttığında enerji yoğunluğu da artmaktadır. Enerji yoğunluğunun artması deşarj kıvılcımını arttırarak yüksek MRR'ye neden olur [22]. Bu hızlı işleme esnasında aşırı ısınan erimiş malzemeler delik giriş ve çıkışlarına yapışarak çapak oluşumuna sebep olmaktadır. Bu durumda akımın artmasıyla delik girişindeki deformasyon faktörü $\left(\mathbf{F} \mathbf{d}_{\mathbf{T}}\right)$, delik çıkışındaki deformasyon faktörünü $\left(\mathbf{F} \mathbf{d}_{\mathbf{B}}\right)$ olumsuz etkilemektedir.

Tablo 6. Ortalama değerlerin ANOVA analizi

\begin{tabular}{rrrrrrrr}
\hline Kaynak & DF & Seq SS & Adj SS & Adj MS & F & P & Katkı (\%) \\
\hline A & 2 & 1527,89 & 1527,89 & 763,943 & 299,34 & 0,003 & 99,1 \\
B & 2 & 117,55 & 117,55 & 58,775 & 23,03 & 0,042 & 7,07 \\
C & 2 & 16,36 & 16,36 & 8,178 & 3,200 & 0,238 & 0,98 \\
Hata & 2 & 5,10 & 5,10 & 2,552 & - & - & - \\
Toplam & 8 & 1666,90 & - & - & - & - & - \\
\hline
\end{tabular}

Adj MS; ortalama kare, Adj SS; ortalama kareler toplamı, Seq SS; kareler toplamının karesi, Df; serbestlik derecesi

Taguchi yöntemiyle yapılan optimizasyon işleminin güvenirliğinin tespiti için tahmin edilen değerlerin güven aralığının belirlenmesi gerekir. Bu amaçla, tahmin edilen $\mathbf{F d}_{\mathbf{T}}, \mathbf{F d}_{\mathbf{B}}$ ve $\boldsymbol{K}^{\circ}$ için güven aralığı $(\mathrm{CI})$ Eşitlik (5) ve (6)'ya göre hesaplanmıştır.

$$
C I=\sqrt{F_{\alpha ; 1 ; f_{e}} x V_{e} x\left(\frac{1}{n_{e f f}}+\frac{1}{r}\right)}
$$


$n_{\text {eff formülde: }}$

$n_{e f f}=\frac{N}{1+\left[T_{d o f}\right]}$

Tablo 7'de Eşitlik 4 ve 5'e ait sembol ve kısaltmalar verilmiştir.

Tablo 7. Güven aralı̆̆ (CI) formül ve sembolleri [23]

\begin{tabular}{rrr}
\hline S. & Sembol & Açılama \\
\hline 1 & $F \alpha ; 1 ; f e$ & F oranı \%95 ( F tablosuna göre) \\
2 & $\alpha$ & Önem düzeyi \\
3 & $f e$ & Serbestlik derecesi hatas1 \\
4 & $V e$ & Hata varyans1 \\
5 & $r$ & Doğrulama için tekrar sayıs1 \\
6 & $n e f f$ & Etkili tekrar sayıs1 \\
7 & $N$ & Toplam deney sayıs1 \\
8 & $T_{d o f}$ & Toplam ana faktör serbestlik derecesi \\
\hline
\end{tabular}

Tablo 8'da $\mathbf{F d}_{\mathbf{T}}, \mathbf{F d}_{\mathbf{B}}$ ve $\boldsymbol{K}^{\mathbf{0}}$ deneysel sonuçlar ve tahmin değerlerinin karşılaştırılması (\%95 güven aralığında) verilmiştir. Tahmin değerlerinin $\% 95$ güven aralığında olduğu görülmektedir. Bu da Taguchi metodu ile yapılan modellemenin sonuçlar için güvenilir olduğunu göstermektedir.

Tablo 8. Modelleme sonucunda elde edilen tahmin değerleri ve güven aralı̆̆

\begin{tabular}{|c|c|c|c|c|c|c|c|c|c|}
\hline \multirow{2}{*}{ No- } & \multicolumn{3}{|c|}{ Deformasyon Faktörü $\left(\mathbf{F d}_{\mathrm{T}}\right)$} & \multicolumn{3}{|c|}{ Deformasyon Faktörü $\left(\mathbf{F d}_{\mathrm{B}}\right)$} & \multicolumn{3}{|r|}{ Kerf açısı $\left(K^{0}\right)$} \\
\hline & $\mathbf{F d}_{\mathbf{T}}$ & Tahmin & $\% 95 \mathrm{CI}$ & $\mathbf{F d}_{\mathbf{B}}$ & Tahmin & $\% 95 \mathrm{CI}$ & $\left(K^{0}\right)$ & Tahmin & $\% 95 \mathrm{CI}$ \\
\hline 1 & 24,26 & 27,32 & $(7,56 ; 47,08)$ & 59,5 & 61,1 & $(23,1 ; 99,2)$ & 1,323 & 0,960 & $(0,139 ; 1,780)$ \\
\hline 2 & 33,05 & 35,25 & $(21,93 ; 48,57)$ & 77,9 & 65,9 & $(40,3 ; 91,6)$ & 0,839 & 0,982 & $(0,429 ; 1,535)$ \\
\hline 3 & 50,51 & 43,18 & $(23,42 ; 62,94)$ & 64,1 & 70,8 & $(32,7 ; 108,8)$ & 0,938 & 1,005 & $(0,185 ; 1,825)$ \\
\hline 4 & 52,33 & 40,31 & $(26,99 ; 53,63)$ & 75,7 & 99,0 & $(73,3 ; 124,6)$ & 0,267 & 0,972 & $(0,419 ; 1,525)$ \\
\hline 5 & 32,60 & 48,24 & $(34,92 ; 61,56)$ & 124,8 & 103,8 & $(78,2 ; 129,5)$ & 1,291 & 0,995 & $(0,442 ; 1,548)$ \\
\hline 6 & 38,19 & 38,72 & $(21,87 ; 55,57)$ & 111,6 & 116,6 & $(84,2 ; 149,1)$ & 1,159 & 1,056 & $(0,356 ; 1,755)$ \\
\hline 7 & 54,85 & 53,30 & $(33,54 ; 73,06)$ & 135,5 & 136,9 & $(98,8 ; 174,9)$ & 1,241 & 0,985 & $(0,165 ; 1,805)$ \\
\hline 8 & 40,60 & 43,78 & $(26,93 ; 60,63)$ & 169,2 & 149,7 & $(117,3 ; 182,2)$ & 1,064 & 1,046 & $(0,346 ; 1,745)$ \\
\hline 9 & 55,40 & 51,71 & $(34,86 ; 68,56)$ & 140,0 & 154,5 & $(122,1 ; 187,0)$ & 0,947 & 1,068 & $(0,369 ; 1,768)$ \\
\hline
\end{tabular}

Tablo 9'da optimum işleme parametreleri ve tahmin değerleri verilmiştir. Taguchi metoduyla elde edilen tahmin değerlerinin \%95 güven aralığında olduğu tespit edilmiştir. Bu sonuçlar Taguchi metodunun mikro EDM işleminde delik deformasyon ve kerf açısı sonuçlarının tahmininde güvenilir bir metot olduğunu göstermektedir.

Tablo 9. Doğrulama testi 


\begin{tabular}{rrrr} 
& & Tahmin & Deneysel \\
\cline { 3 - 4 } Ayar seviyesi & $\mathbf{A}_{\mathbf{1}} \mathbf{B}_{\mathbf{1}} \mathbf{C}_{\mathbf{1}}$ & $\mathbf{A}_{\mathbf{1}} \mathbf{B}_{\mathbf{1}} \mathbf{C}_{\mathbf{2}}$ & $\mathbf{A}_{\mathbf{1}} \mathbf{B}_{\mathbf{1}} \mathbf{C}_{\mathbf{2}}$ \\
\hline $\mathbf{F d}_{\mathbf{T}}$ & 24,259 & 41,837 & 40,984 \\
$\mathbf{F d}_{\mathbf{B}}$ & 59,534 & 42,323 & 42,254 \\
$\boldsymbol{K}^{\mathbf{0}}$ & 1,323 & 0,646 & 0,635 \\
\hline
\end{tabular}

$\mathbf{F d}_{\mathbf{T}}, \mathbf{F d}_{\mathbf{B}}$ ve $\boldsymbol{K}^{\mathbf{0}}$ sonuçlarını etkileyen faktörlerin ideal değerlerinin tespiti için GRA kullanılmıştır.

Tablo 10'de GRA analiz sonuçları verilmiştir. Çok faktörlü problemleri optimize etmek için Taguchi Metodu esaslı GRA kullanılmaktadır [24]. Faktörler arası etki derecesi ise gri ilişkisel derece olarak isimlendirilir. Gri ilişkisel derecesinin büyüklüğ̈̈ (GRG) sonuç ile faktörler arsındaki arasında kuvvetli bir ilişki olduğunun göstergesidir [25]. Yani GRG'nin en büyük değeri faktörlerin sonuçlara olumlu katkı sağladığını göstermektedir [10]. Rank ise GRG değerlerinin sıralamasını vermektedir. Rank sırası 1 olan 1 no'lu deneyde GRG değeri $0,778^{\prime}$ dir. Yani yapılan bu deneyler içinde çok faktörlü değerlendirmeler için en ideal değer 1 no'lu deneyde elde edilmiştir. En kötü şartlara ise (Rank 9) 7 no'lu deneyde ulaşılmıştır.

Tablo 10. Gri ilişkisel derece ve Rank

\begin{tabular}{|c|c|c|c|c|c|c|c|c|c|c|c|}
\hline \multirow{2}{*}{$\begin{array}{r}\text { Deney } \\
\text { No } \\
\end{array}$} & \multicolumn{4}{|c|}{ Normalizasyon } & \multicolumn{2}{|c|}{ Bağımlılık Dizisi } & \multicolumn{3}{|c|}{ Gri İlişki Katsayısı } & \multirow[b]{2}{*}{ GRG } & \multirow[b]{2}{*}{ Rank } \\
\hline & $\mathbf{F d}_{\mathbf{T}}$ & $\mathbf{F d}_{\mathrm{B}}$ & $\left(K^{\mathbf{o}}\right)$ & $\mathbf{F} \mathbf{d}_{\mathbf{T}}$ & $\mathbf{F d}_{\mathbf{B}}$ & $\left(\boldsymbol{K}^{\mathbf{o}}\right)$ & $\mathbf{F} \mathbf{d}_{\mathbf{T}}$ & $\mathbf{F d}_{\mathbf{B}}$ & $\left(\boldsymbol{K}^{\mathbf{0}}\right)$ & & \\
\hline 1 & 1,000 & 1,000 & 0,000 & 0,000 & 0,000 & 1,000 & 1,000 & 1,000 & 0,333 & 0,778 & 1 \\
\hline 2 & 0,718 & 0,832 & 0,458 & 0,282 & 0,168 & 0,542 & 0,639 & 0,749 & 0,480 & 0,623 & 3 \\
\hline 3 & 0,157 & 0,959 & 0,365 & 0,843 & 0,041 & 0,635 & 0,372 & 0,924 & 0,440 & 0,579 & 4 \\
\hline 4 & 0,099 & 0,853 & 1,000 & 0,901 & 0,147 & 0,000 & 0,357 & 0,773 & 1,000 & 0,710 & 2 \\
\hline 5 & 0,732 & 0,406 & 0,030 & 0,268 & 0,594 & 0,970 & 0,651 & 0,457 & 0,340 & 0,483 & 5 \\
\hline 6 & 0,553 & 0,525 & 0,155 & 0,447 & 0,475 & 0,845 & 0,528 & 0,513 & 0,372 & 0,471 & 6 \\
\hline 7 & 0,018 & 0,307 & 0,077 & 0,982 & 0,693 & 0,923 & 0,337 & 0,419 & 0,351 & 0,369 & 9 \\
\hline 8 & 0,475 & 0,000 & 0,245 & 0,525 & 1,000 & 0,755 & 0,488 & 0,333 & 0,399 & 0,407 & 7 \\
\hline 9 & 0,000 & 0,266 & 0,356 & 1,000 & 0,734 & 0,644 & 0,333 & 0,405 & 0,437 & 0,392 & 8 \\
\hline
\end{tabular}

GRG değerlerine ait $\mathrm{S} / \mathrm{N}$ analizi sonuçları Şekil 6'da verilmiştir. $\mathrm{S} / \mathrm{N}$ analizine göre optimum değerler $\mathbf{A}_{1} \mathbf{B}_{1} \mathbf{C}_{2}$ olarak belirlenmiştir.
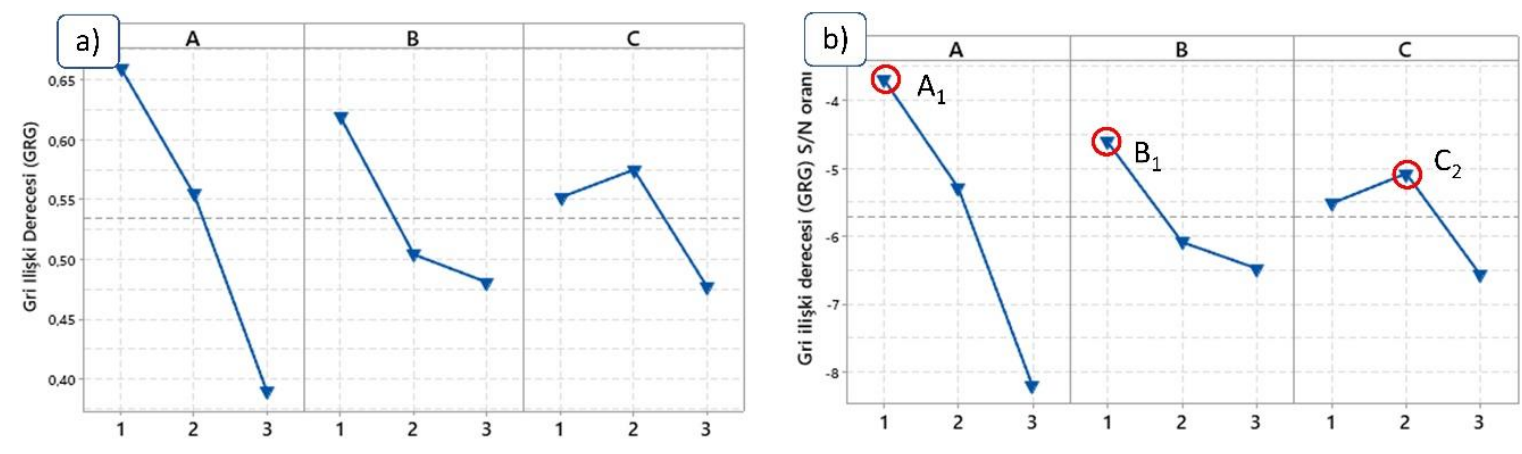

Şekil 6. GRG ortalama ve S/N grafiği

Daha sonra deneysel sonuçlarla tahmin edilen değerlerinin CI dahilinde olup olmadığını belirlemek için ikinci dereceden regresyon analizi uygulanmıştır (Eşitlik 7). Bu test, Taguchi yöntemi kullanılarak tahmin edilen değerler ile deneysel sonuçlar arasındaki ilişkiyi belirlemek için yapılmıştır. Sonuçlar değerlendirildiğinde, tahmin edilen değerlerin regresyon analizinde $\% 95$ güven aralığında kaldığı görülmüştür. 
GRG $=1,0182-0,1352$ A- 0,0692 B- 0,0374 C $\quad\left(R^{2}=\% 86,20\right)$

\section{IV.SONUC}

R65 paslanmaz çeliğin Mikro-EDM yöntemiyle delinmesinde akım (A), vurum süresi $\left(\mathbf{T}_{\mathbf{o n}}\right)$ ve Bekleme süresi $\left(\mathbf{T}_{\text {off }}\right)$ faktörlerinin, delik girişindeki deformasyon faktörü $\left(\mathbf{F d}_{\mathbf{T}}\right)$, delik çıkışındaki deformasyon faktörü $\left(\mathbf{F d}_{\mathbf{B}}\right)$ ve Kerf açısı $\left(\boldsymbol{K}^{\mathbf{0}}\right)$ 'na etkisinin araştırıldığı çalışmada aşağıdaki sonuçlar elde edilmiştir.

- Taguchi metodu ile elde edilen sonuçlara göre en düşük $\mathbf{K}^{\mathbf{0}}, \mathbf{F d}_{\mathbf{T}}$ ve $\mathbf{F} \mathbf{d}_{\mathbf{B}}$ değerleri sırasıyla $0,267 \boldsymbol{K}^{\mathbf{0}} 24,259 \mu$ s ve $59,534 \mu$ s olarak tespit edilmiştir.

- Akımın artmasıyla delik giriş ve çıkışlarındaki deformasyonun arttığı sonucuna ulaşılmıştır. Delik çıkışlarındaki deformasyonun $\left(\mathbf{F d}_{\mathbf{B}}\right)$ delik girişlerine göre daha belirgin olduğu görülmektedir. Akımın artması işleme süresini azaltırken delik kalitesini olumsuz etkilemektedir.

- GRA analizi sonucunda elde edilen tüm parametreler için en ideal değer Rank sırası 1 olan 1 no'lu deneyde elde edilmiştir ve GRG değeri 0,778'dir. GRA yönteminin Mikro EDM işleminde başarılı şekilde uyulabildiğini göstermiştir.

- Deliklerin mikroskop görüntüleri incelendiğinde ideal olan 1 no'lu delik giriş ve çıkışında deformasyonun az olduğu açık şekilde görülmektedir. En kötü şartlarda oluşan 7 no'lu deneyde ise oluşan deformasyon açık şekilde görülmektedir. Delik çıkışında özellikle daha fazla deformasyon oluşmuştur. Ayrıca akımın artması delik çıkışlarındaki deformasyonu arttırmıştır.

- $\mathrm{S} / \mathrm{N}$ analizine göre kerf açısı, delik girişindeki deformasyon, delik çıkışındaki deformasyon ve ortalama çap için en ideal parametreler akım $3 \mathrm{~A}, \mathbf{T}_{\text {on }} 3 \mu \mathrm{s}$ ve $\mathbf{T}_{\text {off }} 2 \mu \mathrm{s}\left(\mathbf{A}_{\mathbf{1}} \mathbf{B}_{\mathbf{1}} \mathbf{C}_{2}\right)$ olarak tespit edilmiştir. Akım ve $\mathbf{T}_{\text {on }}$ düşük değerlerde iyi sonuçlara ulaşılmıştır. Akım ve $\mathbf{T}_{\text {on }}$ artıkça deliklerin deformasyonu ve kerf açısı artmaktadır.

- Yapılan doğrulama test sonuçlarına göre Taguchi metodu ile tahmin edilen değerler ile deneysel sonuçların \%95 güven aralığında olduğu tespit edilmiştir. Bu da Taguchi yönteminin Mikro-EDM işleminde kullanılabilir bir yöntem olduğunu göstermektedir.

- Gelecekte R65 paslanmaz çeliğin Mikro-EDM yöntemiyle delinmesinde delik kalitesinde etkili olabilecek elektrot türü, kullanılan dielektrik sıvısı türü ve sıvı basıncı, elektrot dönme hızı gibi faktörlerin de etkisi araştırılabilir.

\section{KAYNAKLAR}

[1] M. P. Jahan, Y. San Wong, and M. Rahman, "A comparative experimental investigation of deep-hole micro-EDM drilling capability for cemented carbide (WC-Co) against austenitic stainless steel (SUS 304)," The International Journal of Advanced Manufacturing Technology, vol. 46, no. 912, pp. $1145-1160,2010$

[2] V. G. M. V. J. Hadfield and Z. M. E. EDM, "Deep micro-hole drilling for Hadfield steel by electro-discharge machining (EDM)," Materiali in tehnologije, vol. 49, no. 3, pp. 377-386, 2015 
[3] P. C. Kaminski and M. N. Capuano, "Micro hole machining by conventional penetration electrical discharge machine," International Journal of Machine Tools and Manufacture, vol. 43, no. 11, pp. 1143-1149, 2003

[4] Z. Katz and C. Tibbles, "Analysis of micro-scale EDM process," The International Journal of Advanced Manufacturing Technology, vol. 25, no. 9-10, pp. 923-928, 2005

[5] Y.-Y. Tsai and T. Masuzawa, "An index to evaluate the wear resistance of the electrode in micro-EDM," Journal of Materials Processing Technology, vol. 149, no. 1, pp. 304-309, 2004

[6] A. K. Singh, P. K. Patowari, and M. Chandrasekaran, "Experimental study on drilling microhole through micro-EDM and optimization of multiple performance characteristics," Journal of the Brazilian Society of Mechanical Sciences and Engineering, vol. 42, no. 10, pp. 1-14, 2020

[7] N. M. Elsiti, M. Noordin, A. Idris, and F. S. Majeed, "Optimization of maghemite ( $\gamma$-Fe2O3) nano-powder mixed micro-EDM of CoCrMo with multiple responses using gray relational analysis (GRA),"Journal of Physics: Conference Series, vol. 914, no. 1, pp. 1-9, 2017

[8] P. H. A. Kadirvel, "Optimization of the die-sinking micro-EDM process for multiple performance characteristics using the Taguchi-based grey relational analysis," Materiali in tehnologije, vol. 48, no. 1, pp. 27-32, 2014

[9] N. Natarajan and R. Arunachalam, "Optimization of micro-EDM with multiple performance characteristics using Taguchi method and Grey relational analysis," Optimization of micro-EDM with multiple performance characteristics using Taguchi method and Grey relational analysis, vol. 70, pp. 500-505, 2011

[10] M. Ay, U. Çaydaş, and A. Hasçalık, "Optimization of micro-EDM drilling of Inconel 718 superalloy," The International Journal of Advanced Manufacturing Technology, c. 66, s. 5-8, ss. 10151023, 2013

[11] A. Mohanty, G. Talla, and S. Gangopadhyay, "Experimental investigation and analysis of EDM characteristics of Inconel 825," Materials and Manufacturing Processes, c. 29, s. 5, ss. 540-549, 2014

[12] G.-L. Chern and Y. Chuang, "Study on vibration-EDM and mass punching of micro-holes," Journal of Materials Processing Technology, c. 180, s. 1, ss. 151-160, 2006

[13] T. Masuzawa, J. Tsukamoto, and M. Fujino, "Drilling of Deep Microholes by EDM," CIRP Annals, c. 38, s. 1, ss. 195-198, 1989

[14] B. H. Yan, F. Y. Huang, H. M. Chow, and J. Y. Tsai, "Micro-hole machining of carbide by electric discharge machining," Journal of Materials Processing Technology, c. 87, s. 1, ss. 139-145, 1999

[15] L. Tang and Y. F. Guo, "Electrical discharge precision machining parameters optimization investigation on S-03 special stainless steel," The International Journal of Advanced Manufacturing Technology, vol. 70, no. 5, pp. 1369-1376, 2014

[16] M. Sarıkaya and V. Yılmaz, "Optimization and predictive modeling using S/N, RSM, RA and ANNs for micro-electrical discharge drilling of AISI 304 stainless steel," Neural Computing and Applications, vol. 30, no. 5, pp. 1503-1517, 2018 
[17] D. Wang, W. S. Zhao, L. Gu, and X. M. Kang, "A study on micro-hole machining of polycrystalline diamond by micro-electrical discharge machining," Journal of Materials Processing Technology, vol. 211, no. 1, pp. 3-11, 2011

[18] O. Erdem, C. Çoğun, L. Ürtekin, H. B. Özerkan, and İ. Uslan, "The effect of powder mixed and heated dielectric on drilling performance of electric discharge machining (EDM)," Journal of the Faculty of Engineering and Architecture of Gazi University, vol. 31, no. 3, pp. 531-544, 2016

[19] K. Maity and R. K. Singh, "An optimisation of micro-EDM operation for fabrication of microhole," The International Journal of Advanced Manufacturing Technology, vol. 61, no. 9-12, pp. 12211229,2012

[20] S. Dong, Z. Wang, and Y. Wang, "Micro-EDM drilling of high aspect ratio micro-holes and in situ surface improvement in C17200 beryllium copper alloy," Journal of Alloys and Compounds, vol. 727, pp. 1157-1164, 2017

[21] A. Kadirvel, P. Hariharan, and S. Gowri, "Experimental investigation on the electrode specific performance in micro-EDM of die-steel," Materials and Manufacturing Processes, vol. 28, no. 4, pp. 390-396, 2013

[22] B. Pradhan, M. Masanta, B. Sarkar, and B. Bhattacharyya, "Investigation of electro-discharge micro-machining of titanium super alloy," The International Journal of Advanced Manufacturing Technology, vol. 41, no. 11-12, pp. 1094-1106, 2009

[23] S. Akıncioğlu, H. Gökkaya, and İ. Uygur, "The effects of cryogenic-treated carbide tools on tool wear and surface roughness of turning of Hastelloy C22 based on Taguchi method," The International Journal of Advanced Manufacturing Technology, journal article vol. 82, no. 1, pp. 303314, 2016

[24] E. Nas and S. Akıncıoğlu, "Kriyojenik işlem görmüş nikel esaslı süper alaşımın elektroerozyon İşleme performansı optimizasyonu," Akademik Platform Mühendislik ve Fen Bilimleri Dergisi, c. 7, s. 1, ss. 115-126, 2019

[25] E. Yilmaz and F. Güngör, "Gri iliskisel analiz yöntemine göre farkli sertliklerde optimum takim tutucusunun belirlenmesi," in 2. Ulusal Tasarım Imalat ve Analiz Kongresi, Balıkesir, 2010, ss. $1-8$ 